\title{
Novel Superabsorbent Polymer Composites Based on a-Cellulose and Modified-Zeolite: Synthesis, Characterization, Water Absorbency and Water Retention Capacity
}

\section{Enfa Fu}

NJUST: Nanjing University of Science and Technology

\section{Sijia Zhang}

NJUST: Nanjing University of Science and Technology

Yu Luan

NJUST: Nanjing University of Science and Technology

\section{Yuting Zhang}

NJUST: Nanjing University of Science and Technology

\section{Summaira Saghir}

NJUST: Nanjing University of Science and Technology

Zhanggang Xiao ( $\square$ xiaozhg@njust.edu.cn)

NJUST: Nanjing University of Science and Technology https://orcid.org/0000-0002-7836-1397

\section{Research Article}

Keywords: Superabsorbent polymer composites, Cellulose, Modified-zeolite, Water absorbency, Water retention capacity

Posted Date: June 21st, 2021

DOl: https://doi.org/10.21203/rs.3.rs-574009/v1

License: (c) (1) This work is licensed under a Creative Commons Attribution 4.0 International License. Read Full License

Version of Record: A version of this preprint was published at Cellulose on January 27th, 2022. See the published version at https://doi.org/10.1007/s10570-021-04380-x. 


\section{Abstract}

Most superabsorbent polymers (SAP) are fully based on synthetic polymer (from petroleum resources) but costly, nondegradable, and environment-unfriendly. To overcome these disadvantages, biodegradable and renewable natural materials are suggested to be added into SAP. In this article, a new kind of SAP composites was synthesized by using AA, AM, a-cellulose, and modified-zeolite (MZE) as raw materials. The prepared novel SAP composite was analyzed by FTIR, XRD, SEM and TGA. Then, its water absorbency and water retention capacity were evaluated. The AA and AM were successfully grafted on acellulose chains and the introduction of MZE as an inorganic filler which is uniformly dispersed in the SAP composite matrix, both resulting in more undulant and coarser surface with abundant hydrophilic groups for novel SAP composites. By contrast with poly(AA-Co-AM), the water absorbency of prepared novel SAP composites is increased by $93.88 \%$ in distilled water and $89.58 \%$ in $0.9 \mathrm{wt} . \% \mathrm{NaCl}$ solution, respectively. Meanwhile, the retained water time of these SAP composites is $11.2 \mathrm{hs}$ evaluated at $50^{\circ} \mathrm{C}$, increasing the water retention capacity by $71.79 \%$. Moreover, both $T_{\text {onset }}$ and $T_{\text {peak }}$ of prepared novel SAP composites are slightly increased compared with a-cellulose-poly(AA-co-AM), showing the introduction of MZE can slightly improve the thermal stability of novel SAP composites. The excellent water absorbency and retention capacity of novel SAP composites show it can be used as a water-keeping material for agricultural and horticulture applications.

\section{Introduction}

As a soft material, superabsorbent polymer (SAP) can absorb vast amounts of water and maintain the absorbed water under some pressure (Islam et al. 2015). It has some potential applications in hygiene (Wu et al. 2008), horticulture (Khan et al. 2009), agriculture (Seki et al. 2014), biological and tissue engineering (Divakaran et al. 2015). However, most SAP are fully based on synthetic polymers (from petroleum resources), and they are costly, nondegradable, and environment-unfriendly (Guilherme et al. 2015; Wang et al. 2010). To overcome these disadvantages, various kinds of biodegradable and renewable natural materials have been suggested to be added into SAP by many researchers (Feng et al. 2014; Dong et al. 2008).

Cellulose, a natural polysaccharide, presents in the world as the most abundant renewable biomasses, and it has drawn much attention in the preparation of SAP (Nogi et al. 2008; Pourjavadi et al. 2014). There are a high number of active hydroxyl groups on the surface of cellulose, which allows them to be easily grafted with acrylic acid (AA) and acrylamide (AM), and further improves water absorbency of cellulose-based SAP (Li et al. 2013). Moreover, cellulose-based SAP has some excellent performance, such as better biocompatibility, low toxicity, and excellent biodegradability (Wu et al. 2012; Marcì et al. 2006). In spite of these advantages, the improper swelling behavior and lower gel strength of these SAP strength strictly limit their application (Haraguchi et al. 2005).

Recently, the introduction of clay material has been proved to be an available method to make SAP achieve better swelling behavior, higher gel strength and lower production cost (Chen et al. 2016; Lu et al. 
2015; Darder et al. 2017; Zhang et al. 2007). Different clays, such as diatomite, rectorite, and sepiolite, have been used in the preparation of SAP with excellent water absorbency and gel strength. Nevertheless, there is few researches about the incorporation of zeolite in the SAP composites. Zeolite is one of the well-known clay minerals (inorganic filler) (Saghir et al. 2021), and it has many unique advantages, including lower cost and higher thermal stability (Yadav et al. 2012; Anbusagar et al. 2014; Saghir et al. 2020). After modified by $\mathrm{NaOH}$ solution, modified-zeolite (MZE) has a larger surface area, stronger adsorption capacity, and more reactive hydroxide radical group on the surface, thus it could react with AA and AM to prepare SAP (Fu et al. 2016). Meanwhile, MZE has strong interfacial interactions with polymer in the SAP composites, which could lead to better water absorbency, appropriate swelling behavior and higher thermal stability. Therefore, the introduction of cellulose and/or MZE is an important way to prepare SAP composites with higher performance.

In this work, a new kind of superabsorbent polymer (SAP) composites was prepared by using AA, AM, acellulose, and MZE as raw materials. Cellulose and MZE are both introduced to traditional SAP matrix. The prepared novel SAP composite was analyzed by Fourier transform infrared spectrum (FTIR), X-ray diffraction (XRD), scanning electron microscopy (SEM) and thermal gravimetric analysis (TGA). The water absorbency of SAP composites was investigated in $0.9 \% \mathrm{NaCl}$ solution and distilled water, respectively. Also, the swelling kinetics and water retention capacity of these SAP composites were studied. As expected, the obtained novel SAP composite exhibits outstanding water absorbency and water retention capacity.

\section{Experimental Section}

\section{Materials}

The Acrylamide (AM, 99\%), Acrylic acid (AA, 99\%), Hydrochloric acid ( $\mathrm{HCl}, 36-38 \%)$, Sodium hydroxide ( $\mathrm{NaOH}, 96 \%)$, Potassium persulfate (KPS, 99.5\%), N, N'-methylenebisacrylamide (MBA, $99 \%$ ) and zeolite (ZE) were purchased from Aladdin Industrial Corporation. The inhibitor in AA was removed by reduced pressure distillation before use. The cellulose powder (a-cellulose, $25 \mu \mathrm{m}$ of average particle diameter) was supplied by Shanghai Mackin Biochemical Co., Ltd. All other chemicals were of analytical grade and used without purification.

Pretreatment of Modified-zeolite (MZE)

To prepare modified zeolite (MZE), $10 \mathrm{~g}$ ZE was placed in a vacuum oven for $20 \mathrm{hs}$ at $100^{\circ} \mathrm{C}$. After that ZE with $100 \mathrm{ml} \mathrm{NaOH}$ solution was mixed in a dried flask with magnetic stirring bar. Then the mixture was heated at $80^{\circ} \mathrm{C}$ for $4 \mathrm{hs}$ and washed six times with deionized water. Finally, MZE was grounded and sieved through a 140-mesh sieve, with $5 \mu \mathrm{m}$ average particle diameter, and saved in a desiccator for further use.

Preparation of novel SAP composites (a-cellulose-g-poly(AA-co-AM)/MZE) 
$5 \mathrm{~g} \mathrm{AA}$ was neutralized with $50 \mathrm{ml} \mathrm{NaOH}$ solution in an ice-water bath. $1.5 \mathrm{~g} \mathrm{AM}$ and a certain amount of MZE were ultrasonically dispersed in a mixture solution for 20 mins. Meanwhile, about $0.35 \mathrm{~g}$ a-cellulose was dispersed in $100 \mathrm{ml}$ distilled water at $75^{\circ} \mathrm{C}$ for $4 \mathrm{hs}$ to make a-cellulose swelling. To remove dissolved oxygen, the $A M, A A$, and MZE mixture solution was transferred into the swollen a-cellulose to premix at $40^{\circ} \mathrm{C}$ for 90 min under the $\mathrm{N}_{2}$ atmosphere. The mixture was heated to $55^{\circ} \mathrm{C}$, and then $0.02 \mathrm{~g} \mathrm{KPS}$ was added into it. After 20 mins, $0.0025 \mathrm{~g}$ cross-linking agent MBA was added into the former mixture. Then, the mixture was heated up to $65^{\circ} \mathrm{C}$ for 4 hs under $\mathrm{N}_{2}$ atmosphere, then it was repeatedly washed with deionized water. The product was dried at $50^{\circ} \mathrm{C}$ for $100 \mathrm{hs}$. Finally, dry SAP composites were cut for further characterization. All drying treatments were occurred in the vacuum environment.

\section{Characterizations}

The samples were analyzed by FTIR (Nicolet iS10) using KBr disk method (Saghir et al. 2020) and the wavenumber range was $4000-500 \mathrm{~cm}^{-1}$. 32 scans with a resolution of $4 \mathrm{~cm}^{-1}$ were averaged to obtain each spectrum.

The morphology of samples was observed by SEM (Hitachi S-4800). The glass slides containing samples were covered with a layer of gold, making them conductive under the electron beam.

The crystal form of samples was analyzed in the range of $2 \theta=5^{\circ}-50^{\circ}$ (interval of $0.05^{\circ}$ ) by XRD (Bruker D8) through Cu Ka radiation.

The thermal stability of samples was estimated by TGA (PerkinElmer SDTQ600). The samples were heated under $\mathrm{N}_{2}$ atmosphere from $50^{\circ} \mathrm{C}$ to $600^{\circ} \mathrm{C}$ at a heating rate of $10^{\circ} \mathrm{C} / \mathrm{min}$.

Water absorbency experiment

$0.1 \mathrm{~g}$ SAP composites were immersed in the solution at room temperature to reach swelling equilibrium. Then, SAP composites were extracted from the solution, and the water absorbency $(Q)$ of SAP composites was measured with Eq. (1).

$$
Q(\mathrm{~g} / \mathrm{g})=\frac{M_{\mathrm{t}}-M_{\mathrm{d}}}{M_{\mathrm{d}}}
$$

Where $M_{\mathrm{t}}$ and $M_{\mathrm{d}}$ are the weight of the swollen and dry SAP composites, respectively.

Water retention study

The water retention capacity of SAP composites was evaluated at $50^{\circ} \mathrm{C}$ by the auto mass measurement experiment developed by our group (Chen et al. 2016). The water retention (WR) of SAP composites was calculated by Eq. (2).

$$
W R(\%)=\left(\frac{W_{\mathrm{i}}}{W_{0}}\right) \times 100 \%
$$


Where $W_{\mathrm{i}}$ and $W_{0}$ are the weight of SAP composites at time $t(\mathrm{~min})$ during water retention test and swollen SAP composites, respectively.

\section{Results And Discussion}

Novel SAP composites formation mechanism

The proposed reaction mechanism of novel SAP composites is shown in Fig. 1. First, the a-cellulose is swollen in the distilled water. KPS, a free radical initial agent, forms sulphate anion-radicals which can cleave $\mathrm{H}^{+}$from the hydroxyl group of a-cellulose to form alkoxy radicals. The alkoxy radicals initiate the polymerization of $A A$ and $A M$, leading to a graft copolymer of poly(AA-co-AM) onto a-cellulose chains. During the graft polymerization, the cross-linker (MBA) forms a cross-linked network between the growing polymer chains by the end vinyl groups. At the same time, modified-zeolite (MZE) has a highly active silanol ( $\mathrm{Si}-\mathrm{OH})$ group, and it reacts with the carboxylic acid $(-\mathrm{COOH})$ group to promote MZE particles into the composite network. Moreover, MZE serves as a cross-linked point to increase the intensity of the cross-linked network. In general, novel SAP composites were prepared by grafting copolymerization of AA and AM onto a-cellulose chains and the introduction of MZE as an inorganic filler, and similar reaction mechanism has also been illustrated in previous studies (Pourjavadi et al. 2007; Mukerabigwi et al. 2015; Dai et al. 2017).

FTIR analysis

Figure 2 displays the FTIR results of prepared samples. For MZE, the absorption peak at $970 \mathrm{~cm}^{-1}$ is attributed to the stretching vibration of the Si-O-Si group, and the absorption peak at $522 \mathrm{~cm}^{-1}$ is attributed to the bending vibration of Si-O-Al (Zhang et al. 2007). For a-cellulose, the stretching vibration of $\mathrm{C}-\mathrm{H}$ and $\mathrm{C}-\mathrm{O}-\mathrm{C}$ groups appear at $2850 \mathrm{~cm}^{-1}$ and $1032 \mathrm{~cm}^{-1}$, respectively. The absorption peaks at around $3372 \mathrm{~cm}^{-1}$ and $1310 \mathrm{~cm}^{-1}$ are attributed to the bending and stretching vibration of $-\mathrm{OH}$ group (Saghir et al. 2021). The absorption peak at $1053 \mathrm{~cm}^{-1}$ is related to $\beta-(1,4)$ glycosidic bonds of cellulose. For poly(AA-co-AM), the absorption peak at $2941 \mathrm{~cm}^{-1}$ is ascribed to the stretching vibration of the $\mathrm{C}-\mathrm{H}$ group. The absorption peaks at around $1541 \mathrm{~cm}^{-1}$ and $1415 \mathrm{~cm}^{-1}$ appear due to the asymmetrical and symmetrical stretching vibration of the $-\mathrm{COO}^{-}$group. The absorption peak at $1669 \mathrm{~cm}^{-1}$ is ascribed to carboxamide (Bao et al. 2011).

Compared curve (d) with the curve (a-c) in Fig. 2, the characteristic absorption peaks of MZE, a-cellulose, and poly(AA-co-AM) all appear in the spectra of novel SAP composites. The absorption peaks at 1550 $\mathrm{cm}^{-1}$ and $1404 \mathrm{~cm}^{-1}$ are strengthened, attributing to the asymmetric stretching vibration of a large amount of $\mathrm{C}=0$ groups. Additionally, the absorption peak at $1670 \mathrm{~cm}^{-1}$ is obviously strengthened, attributing to the reaction between the $-\mathrm{COOH}$ group of a-cellulose-poly(AA-Co-AM) and -OH group of MZE (Bao et al. 2011). The results suggest the desired product (novel SAP composites) is successfully 
synthesized. Moreover, the broad characteristic peak at $3450-3310 \mathrm{~cm}^{-1}$ is ascribed to vibration stretching of abundant hydrophilic groups on novel SAP composites.

XRD analysis

The crystalline pattern of prepared samples was performed with XRD. The a-cellulose displays obvious peaks at $15.3^{\circ}$ and $22.9^{\circ}$, which are related to cellulose I in nature (French 2014). These peaks of acellulose in the patterns of a-cellulose-g-poly(AA-co-AM) disappear, indicating that the original crystal structure of a-cellulose is destroyed in the process of graft polymerization, so a-cellulose forms an amorphous state to achieve better water absorbency. For SAP composites, the weak diffraction peak at $21.9^{\circ}-24.1^{\circ}$ is attributed to the change of crystalline phase (Mukerabigwi et al. 2015). Moreover, the characteristic diffraction peaks of MZE disappear in the novel SAP composite, indicating that the MZE is uniformly dispersed in the SAP composite matrix (Dai et al. 2017).

SEM Analysis

The surface morphology of ZE, MZE, a-cellulose, a-cellulose-g-poly(AA-co-AM), and novel SAP composites is shown in Fig. 4. As can be seen from Fig. 4(a-b), MZE has a rougher and looser surface with a high specific surface area compared with ZE. It also has clear layered structure with gaps which are conducive to the absorption of water molecules. The a-cellulose shows long-strip structure, which is used as target macromolecules to be grafted and copolymerized with monomers under the action of the initiator. Compared with Fig. 4(a-d), novel SAP composites present a more comparatively coarser and undulant surface, attributing to the introduction of MZE into its surface. The coarser and undulant surface shows that novel SAP composites have a larger superficial area, which can enhance the water absorbency.

Water absorbency

The water absorbency of samples was measured in distilled water and $0.9 \mathrm{wt} . \% \mathrm{NaCl}$ solution and the results are displayed in Fig. 5. As seen from Fig. 5, the water absorbency of novel SAP composites is better than that of other samples in distilled water and $0.9 \mathrm{wt} . \% \mathrm{NaCl}$ solution, respectively. It is obviously observed that the water absorbency of samples in $0.9 \mathrm{wt} . \% \mathrm{NaCl}$ solution is apparently lower than that of distilled water. $\mathrm{Na}^{+}$mainly causes this phenomenon in the solution (the penetration of $\mathrm{Na}^{+}$into crosslinked network decreases the water absorbency of these samples). After the introduction of MZE and acellulose, the water absorbency of novel SAP composites is increased by $93.88 \%$ (from $350.28 \pm 3.16 \mathrm{~g} / \mathrm{g}$ to $679.13 \pm 5.49 \mathrm{~g} / \mathrm{g}$ ) in distilled water, while it is increased by $89.58 \%$ (from $46.65 \pm 1.78 \mathrm{~g} / \mathrm{g}$ to $88.46 \pm$ $2.36 \mathrm{~g} / \mathrm{g}$ ) in $0.9 \mathrm{wt} . \% \mathrm{NaCl}$ solution compared with poly(AA-Co-AM). Combined with SEM, it is found that novel SAP composites have larger superficial area after the introduction of MZE and a-cellulose, which is able to improve the surface adsorption (Zhang et al. 2007). Moreover, both MZE and a-cellulose have large amounts of hydrophilic groups. In summary, the water absorbency of novel SAP composites is obviously improved after the introduction of MZE and a-cellulose. 
Figure 6 shows the water absorbency of novel SAP composites with different MZE contents. The water absorbency of novel SAP composites is first increased and then decreased as the MZE content is increased, as displayed in Fig. 6. The highest water absorbency of these SAP composites in distilled water and in $0.9 \mathrm{wt} . \% \mathrm{NaCl}$ solution was achieved almost synchronously when the MZE content is $6 \mathrm{wt} . \%$. A large number of pores in MZE accommodate more water molecules with the increase of the internal pore volume. Moreover, MZE can serve as a cross-linked point, which promotes formation of cross-linked network to enhanced water absorbency ( $L i$ et al. 2015). When the content of MZE increases beyond the optimal value, MZE may exist in the form of physical filling, and it produces agglomeration, which will form steric hindrance between polymer chains to make it difficult for the reaction raw materials to evenly disperse in the novel SAP composite (Liang et al. 2009). The results show the optimal addition content of MZE in the novel SAP composite is $6 \mathrm{wt}$.\%, which can obviously enhance the water absorbency. Therefore, novel SAP composites when the addition content of MZE is $6 \mathrm{wt} . \%$ were prepared which used for further investigation on swelling kinetic, water retention capacity and TG analysis.

Swelling kinetics

Figure 7 shows the swelling process of prepared samples in distilled water, respectively. It is obviously observed that the time needed to reach swelling equilibrium of novel SAP composites is shorter than that of poly(AA-co-AM) and a-cellulose-g-poly(AA-co-AM). The swelling rate of novel SAP composites is rapidly increased within the first $30 \mathrm{~min}$ and then slowly increased to $679.13 \mathrm{~g} \cdot \mathrm{g}^{-1}$ until reaching its equilibrium (55 $\mathrm{min}$ ). Moreover, the swelling rate of novel SAP composites is remarkably increased compared with a-cellulose-g-poly(AA-co-AM) $\left(440.23 \mathrm{~g} \cdot \mathrm{g}^{-1}\right.$ at $55 \mathrm{~min}$ ) and poly(AA-co-AM) $\left(350.60 \mathrm{~g} \cdot \mathrm{g}^{-1}\right.$ at $55 \mathrm{~min}$ ). The results show the addition of MZE and a-cellulose affects the swelling kinetics of SAP composites (it is related to surface area and swelling ability (Zhang et al. 2006)). The combination of acellulose and MZE into the polymer network can enhance swelling rate due to the $-\mathrm{OH}$ groups, increasing the affinity of novel SAP composites to water molecules. MZE also strengthens the cross-linked network of novel SAP composites and it provides more free volume to allow water molecules to penetrate novel SAP composites.

The swelling kinetics can be calculated by Eq. (3), which is based on the Voigt-based viscoelastic model (Kabiri et al. 2003; Irani et al. 2013).

$S_{\mathrm{t}}=P\left(1-e^{\frac{-t}{\mathrm{r}}}\right)$

where $S_{\mathrm{t}}\left(\mathrm{g} \cdot \mathrm{g}^{-1}\right)$ is the swelling property of SAP composites at some moment, $P\left(\mathrm{~g} \cdot \mathrm{g}^{-1}\right)$ is the power parameter, and $\mathrm{r}(\mathrm{min})$ is the rate parameter (the time required for the sample to reach $63 \%$ of its final swelling).

As shown in Fig. 7, the fitted curves of swollen samples are consistent with experimental results. The $r$ is $9.57 \mathrm{~min}$, and $P$ for novel SAP composites is $681.16 \mathrm{~g} \cdot \mathrm{g}^{-1}$, the $\mathrm{r}$ is $17.22 \mathrm{~min}$, and $P$ is $465.34 \mathrm{~g} \cdot \mathrm{g}^{-1}$ for acellulose-g-poly(AA-co-AM), and $r$ and $P$ for poly(AA-co-AM) are $23.79 \mathrm{~min}$ and $397.1 \mathrm{~g} \cdot \mathrm{g}^{-1}$, respectively. 
The $P$-value reflects better water absorbency, and the r value reflects the swelling rates (Wang et al. 2009). It is observed that the $r$ is the minimum and the $P$ is the maximum for novel SAP composites. The results indicate that novel SAP composites can provide a better water absorbency and a greater swelling rate after the introduction of MZE and a-cellulose.

Water retention capacity

The water retention capacity of samples was evaluated at $50^{\circ} \mathrm{C}$ by using the auto mass measurement experiment, displayed in Fig. 8. It is obviously noticed that the absorbed water is gradually decreased as the time is increasing. Moreover, novel SAP composites significantly maintain more water compared with the other two samples at the same time. At $5 \mathrm{hs}$, the weight loss of water in swollen novel SAP composites is about $51.1 \%$ while a-cellulose-g-poly(AA-co-AM) is about $73.9 \%$ and poly(AA-co-AM) is about $92.8 \%$. By contrast with poly(AA-co-AM), the retained water time of novel SAP composites is increased from 6.5 hs to $11.2 \mathrm{hs}$, increasing the retained water time by $71.79 \%$. Results show the water retention capacity of novel SAP composites is evidently improved. The introduction of MZE and acellulose can resist shrinkage of SAP composite matrix as dried. Moreover, more absorbed water is fixed in the cross-linked network of novel SAP composites, and the release of this water needs more energy, contributing to the enhanced water retention capacity (Li et al. 2004).

Thermal behavior analysis

The effect of the introduction of MZE on the thermal performance of novel SAP composites was further examined by TGA, and the analysis is represented in Fig. 9 and Table 1.

For a-cellulose-g-poly(AA-co-AM), four mass loss stages are observed. The first stage in a temperature range of $55-105^{\circ} \mathrm{C}$ with about $12 \%$ mass loss is ascribed to the evaporation of water moisture (Seki et al. 2014). The second loss stage between $105^{\circ} \mathrm{C}$ and $346^{\circ} \mathrm{C}$ is attributed by decomposition of a-cellulose (Fu et al. 2016; Etminani-Isfahani et al. 2020). The third mass loss stage between $346^{\circ} \mathrm{C}$ and $410^{\circ} \mathrm{C}$ is attributed by the decomposition of some short or straight chains of a-cellulose-g-poly(AA-co-AM) (Liang et al. 2009). The fourth mass loss stage between $410^{\circ} \mathrm{C}$ and $510^{\circ} \mathrm{C}$ is ascribed to the degradation of grafted chains in the cross-linked network (Bee et al. 2014). The TG curve of novel SAP composites contains four similar stages compared with a-cellulose-g-poly(AA-co-AM). However, $T_{\text {onset }}$ of novel SAP composites is increased from $63.5^{\circ} \mathrm{C}$ to $63.8^{\circ} \mathrm{C}$, and the residual rate is increased from $32.9-34.5 \%$.

It is obviously observed in Table 1 that the $T_{10 \%}, T_{50 \%}$ and $T_{\text {peak }}$ (the temperatures at a maximum decomposition rate of each step) of novel SAP composites are increased compared with a-cellulose-gpoly(AA-Co-AM), respectively. The above results indicate that the addition of MZE can slightly improve the thermal stability of novel SAP composites. MZE has higher thermal stability which can serve as a crosslinked point to enhance the intensity of cross-linked networks which delays the thermal decomposition of novel SAP composites, and it has strong interactions with polymers in the novel SAP composites ( $\mathrm{Li}$ et al. 2015; Etminani-Isfahani et al. 2020), both resulting in improvement of thermal stability. However, the 
addition content of MZE is only 6 wt.\% now and its effect on the thermal stability of novel SAP composites is not significant yet.

Table 1

Different characteristic temperatures in TG and DTG experiments

\begin{tabular}{|c|c|c|c|c|c|c|c|c|}
\hline \multirow[t]{2}{*}{ Samples } & \multicolumn{4}{|l|}{ TG } & \multicolumn{4}{|c|}{ DTG } \\
\hline & $\begin{array}{l}T_{\text {onset }} / \\
{ }^{\circ} \mathrm{C}\end{array}$ & $\begin{array}{l}T_{10 \%} / \\
{ }^{\circ} \mathrm{C}\end{array}$ & $\begin{array}{l}T_{50 \%} / \\
{ }^{\circ} \mathrm{C}\end{array}$ & $\begin{array}{l}\text { Residual } \\
\text { rate/\% }\end{array}$ & $T_{\text {pea }}$ & $1{ }^{\circ} \mathrm{C}$ & & \\
\hline $\begin{array}{l}\text { a-cellulose-g-poly(AA-co- } \\
\text { AM) }\end{array}$ & 63.5 & 75.1 & 461.8 & 32.9 & 64 & 318 & 369 & 439 \\
\hline novel SAP composites & 63.8 & 77.2 & 476.7 & 34.5 & 63 & 330 & 372 & 450 \\
\hline
\end{tabular}

\section{Conclusion}

A new kind of SAP composites was successfully synthesized by grafting AA and AM onto a-cellulose chains and the introducing of MZE as an inorganic filler. By contrast with poly(AA-Co-AM), the prepared novel SAP composites have an undulant and coarse surface with abundant hydrophilic groups, and its water absorbency is increased by $93.88 \%$ (from $350.28 \pm 3.16 \mathrm{~g} / \mathrm{g}$ to $679.13 \pm 5.49 \mathrm{~g} / \mathrm{g}$ ) in distilled water while it is increased by $89.58 \%$ (from $46.65 \pm 1.78 \mathrm{~g} / \mathrm{g}$ to $88.46 \pm 2.36 \mathrm{~g} / \mathrm{g}$ ) in $0.9 \mathrm{wt} . \% \mathrm{NaCl}$ solution. The swelling kinetic mechanism of novel SAP composites agrees with Voigt-based viscoelastic model, and the results show that it has a greater swelling rate. Meanwhile, the retained water time of novel SAP composites is increased from $6.5 \mathrm{hs}$ to $11.2 \mathrm{hs}$, indicating its water retention capacity is increased by $71.79 \%$. Moreover, the addition of MZE can slightly improve the thermal stability of novel SAP composites. The excellent water absorbency and water retention capacity of novel SAP composites show that this method for a-cellulose-g-poly(AA-co-AM)/MZE can be applicable to a variety of other inorganic fillers and polymer composite systems for preparing more SAP composites.

\section{Declarations}

Acknowledgements This work was supported by National Natural Science Foundation of China (No. 22075146).

Authors' contribution Enfa Fu, Sijia Zhang and Yu Luan contributed equally to this work. Enfa Fu conceived the idea and designed the experiments. Sijia Zhang contributed to the material fabrication. Yu Luan conducted the thermal properties measurement and analyzed the corresponding results. Yuting Zhang and Summaira Saghir were responsible for the SEM images and FT-IR measurements. Enfa Fu, Sijia Zhang and Yu Luan co-wrote and revised the manuscript. All authors commented on the final manuscript. 
Conflict of interest The authors declare that there are no financial and personal relationships with other people or organizations that could inappropriately influence their work in this paper. All the authors listed have approved the manuscript enclosed.

Ethical approval All authors state that they adhere to the Ethical Responsibilities of Authors.

Human or animal rights This study has followed compliance with ethical standards. There are no animal studies or human participants involvement in the study.

\section{References}

1. Anbusagar N R R, Giridharan P K, Palanikumar K (2014) Effect of nanomodified polyester resin on hybrid sandwich laminates. Materials and Design 54:507-514

2. Bao Y, Ma J, Li N (2011) Synthesis and swelling behaviors of sodium carboxymethyl cellulose-gpoly(AA-co-AM-co-AMPS)/MMT superabsorbent hydrogel. Carbohydrate Polymers 84(1):76-82

3. Bee S-T, Ratnam C T, Sin L T, Tee T-T, Hui D, Kadhum A A H, Rahmat A R, Lau J (2014) Effects of electron beam irradiation on mechanical properties and nanostructural-morphology of montmorillonite added polyvinyl alcohol composite. Composites Part B: Engineering 63:141-153

4. Chen J, Zhang W, Li X (2016) Preparation and characterization of konjac glucomannan-acrylic aciddiatomite composites. Polymer Composites 37(12):3384-3390

5. Chen M, Zhang Y, Dong C, Xiao Z (2016) On-line auto mass measurement of residual solvent mass and its influence on mechanical properties of propellants. Propellants, Explosives, Pyrotechnics 41(6):972-977

6. Dai H, Huang H (2017) Enhanced swelling and responsive properties of pineapple peel carboxymethyl cellulose-g-poly(acrylic acid-co-acrylamide) superabsorbent hydrogel by the introduction of carclazyte. Journal of Agricultural and Food Chemistry 65(3):565-574

7. Darder M, Matos C R S, Aranda P, Gouveia R F, Ruiz-Hitzky E (2017) Bionanocomposite foams based on the assembly of starch and alginate with sepiolite fibrous clay. Carbohydrate Polymers 157:19331939

8. Divakaran A V, Torris At A, Lele A K, Badiger M V (2015) Porous poly(ethylene glycol)-polyurethane hydrogels as potential biomaterials. Polymer International 64(3):397-404

9. Dong H, Xu Q, Li Y, Mo S, Cai S, Liu L (2008) The synthesis of biodegradable graft copolymer cellulose-graft-poly(L-lactide) and the study of its controlled drug release. Colloids and Surfaces B: Biointerfaces 66(1):26-33

10. Etminani-Isfahani N, Mohammadbagheri Z, Rahmati A (2020) 4-(6-Aminohexyl) amino-4-oxo-2butenoic acid as a novel hydrophilic monomer for synthesis of cellulose-based superabsorbents with high water absorption capacity. Carbohydrate Polymers 250:116959

11. Feng E, Ma G, Wu Y, Wang H, Lei Z (2014) Preparation and properties of organic-inorganic composite superabsorbent based on xanthan gum and loess. Carbohydrate Polymers 111:463-468 
12. French A (2014) Idealized powder diffraction patterns for cellulose polymorphs. Cellulose 21(2):885896

13. Fu L, Cao T, Lei Z, Chen H, Shi Y, Xu C (2016) Superabsorbent nanocomposite based on methyl acrylic acid-modified bentonite and sodium polyacrylate: Fabrication, structure and water uptake. Materials and Design 94:322-329

14. Guilherme M R, Aouada F A, Fajardo A R, Martins A F, Paulino A T, Davi M F T, Rubira A F, Muniz E C (2015) Superabsorbent hydrogels based on polysaccharides for application in agriculture as soil conditioner and nutrient carrier: A review. European Polymer Journal 72:365-385

15. Haraguchi K, Li H J, Matsuda K, Takehisa T, Elliott E (2005) Mechanism of forming organic/inorganic network structures during in-situ free-radical polymerization in PNIPA-clay nanocomposite hydrogels. Macromolecules 38(8):3482-3490

16. Irani M, Ismail H, Ahmad Z (2013) Preparation and properties of linear low-density polyethylene-gpoly (acrylic acid)/organo-montmorillonite superabsorbent hydrogel composites. Polymer Testing 32(3):502-512

17. Islam M S, Rahaman M S, Yeum J H (2015) Electrospun novel super-absorbent based on polysaccharide-polyvinyl alcohol-montmorillonite clay nanocomposites. Carbohydrate Polymers 115:69-77

18. Kabiri K, Omidian H, Hashemi S A, Zohuriaan-Mehr M J (2003) Synthesis of fast-swelling superabsorbent hydrogels: effect of crosslinker type and concentration on porosity and absorption rate. European Polymer Journal 39(7):1341-1348

19. Khan F, Tare R S, Oreffo R O, Bradley M (2009) Versatile biocompatible polymer hydrogels: scaffolds for cell growth. Angewandte Chemie International Edition 48(5):978-982

20. Li A, Wang A, Chen J (2004) Studies on poly(acrylic acid)/attapulgite superabsorbent composite. I. synthesis and characterization. Journal of Applied Polymer Science 92(3):1596-1603

21. Li J, Corma A, Yu J (2015) Synthesis of new zeolite structures. Chemical Society Reviews 44(20):7112-7127

22. Li Y, Huang G, Zhang X, Li B, Chen Y, Lu T, Lu T J, Xu F (2013) Magnetic hydrogels and their potential biomedical applications. Advanced Functional Materials 23(6):660-672

23. Liang R, Yuan H, Xi G, Zhou Q (2009) Synthesis of wheat straw-g-poly(acrylic acid) superabsorbent composites and release of urea from it. Carbohydrate Polymers 77(2):181-187

24. Lu Y, Chang P R, Zheng P V, Ma X (2015) Porous 3D network rectorite/chitosan gels: Preparation and adsorption properties. Applied Clay Science 107:21-27

25. Marcì G, Mele G, Palmisano L, Pulito P, Sannino A (2006) Environmentally sustainable production of cellulose-based superabsorbent hydrogels. Green Chemistry 8(5):439-444

26. Mukerabigwi J F, Lei S, Wang H, Luo S, Ma X, Qin J, Huang X, Cao Y (2015) Synthesis and properties of a novel ecofriendly superabsorbent hydrogel nanocomposite based on xyloglucan-graftpoly(acrylic acid)/diatomite. RSC Advances 5(102):83732-83742 
27. Nogi M, Yano H (2008) Transparent nanocomposites based on cellulose produced by bacteria offer potential innovation in the electronics device industry. Advanced Materials 20(10):1849-1852

28. Pourjavadi A, Barzegar S, Zeidabadi F (2007) Synthesis and properties of biodegradable hydrogels of $\mathrm{K}$-carrageenan grafted acrylic acid-co-2-acrylamido-2-methylpropanesulfonic acid as candidates for drug delivery systems. Reactive \& Functional Polymers 67(7):644-654

29. Pourjavadi A, Mahdavinia G R (2014) Superabsorbency, pH-sensitivity and swelling kinetics of partially hydrolyzed chitosan-g-poly(acrylamide) hydrogels. Turkish Journal of Chemistry 30(5):595608

30. Saghir S, Fu E, Xiao Z (2020) Synthesis of CoCu-LDH nanosheets derived from zeolitic imidazole framework-67 (ZIF-67) as an efficient adsorbent for azo dye from waste water. Microporous and Mesoporous Materials 291:110010

31. Saghir S, Xiao Z (2021) Hierarchical mesoporous ZIF-67@LDH for efficient adsorption of aqueous Methyl Orange and Alizarine Red S. Powder Technology 377:453-463

32. Seki Y, Altinisik A, Demircioğlu B, Tetik C (2014) Carboxymethylcellulose (CMC)-hydroxyethylcellulose (HEC) based hydrogels: synthesis and characterization. Cellulose 21(3):1689-1698

33. Wang J, Wang W, Wang A (2010) Synthesis, characterization and swelling behaviors of hydroxyethyl cellulose-g-poly(acrylic acid)/attapulgite superabsorbent composite. Polymer Engineering and Science 50(5):1019-1027

34. Wang W, Wang A (2009) Preparation, characterization and properties of superabsorbent nanocomposites based on natural guar gum and modified rectorite. Carbohydrate Polymers 77(4):891-897

35. Wu F, Zhang Y, Liu L, Yao J (2012) Synthesis and characterization of a novel cellulose-g-poly(acrylic acid-co-acrylamide) superabsorbent composite based on flax yarn waste. Carbohydrate Polymers 87(4):2519-2525

36. Wu L, Liu M, Rui L (2008) Preparation and properties of a double-coated slow-release NPK compound fertilizer with superabsorbent and water-retention. Bioresource Technology 99(3):547-554

37. Yadav M, Rhee K Y (2012) Superabsorbent nanocomposite (alginate-g-PAMPS/MMT): synthesis, characterization and swelling behavior. Carbohydrate Polymers 90(1):165-173

38. Zhang J, Li A, Wang A (2006) Study on superabsorbent composite. Vl. Preparation, characterization and swelling behaviors of starch phosphate-graft-acrylamide/attapulgite superabsorbent composite. Carbohydrate Polymers 65(2):150-158

39. Zhang J, Qin W, Wang A (2007) Synthesis and characterization of chitosan-g-poly(acrylic acid)/attapulgite superabsorbent composites. Carbohydrate Polymers 68(2):367-374

40. Zhang J, Wang L, Wang A (2007) Preparation and properties of chitosan-g-poly(acrylic acid)/montmorillonite superabsorbent nanocomposite via in situ intercalative polymerization. Industrial \& Engineering Chemistry Research 46(8):2497-2502

\section{Figures}




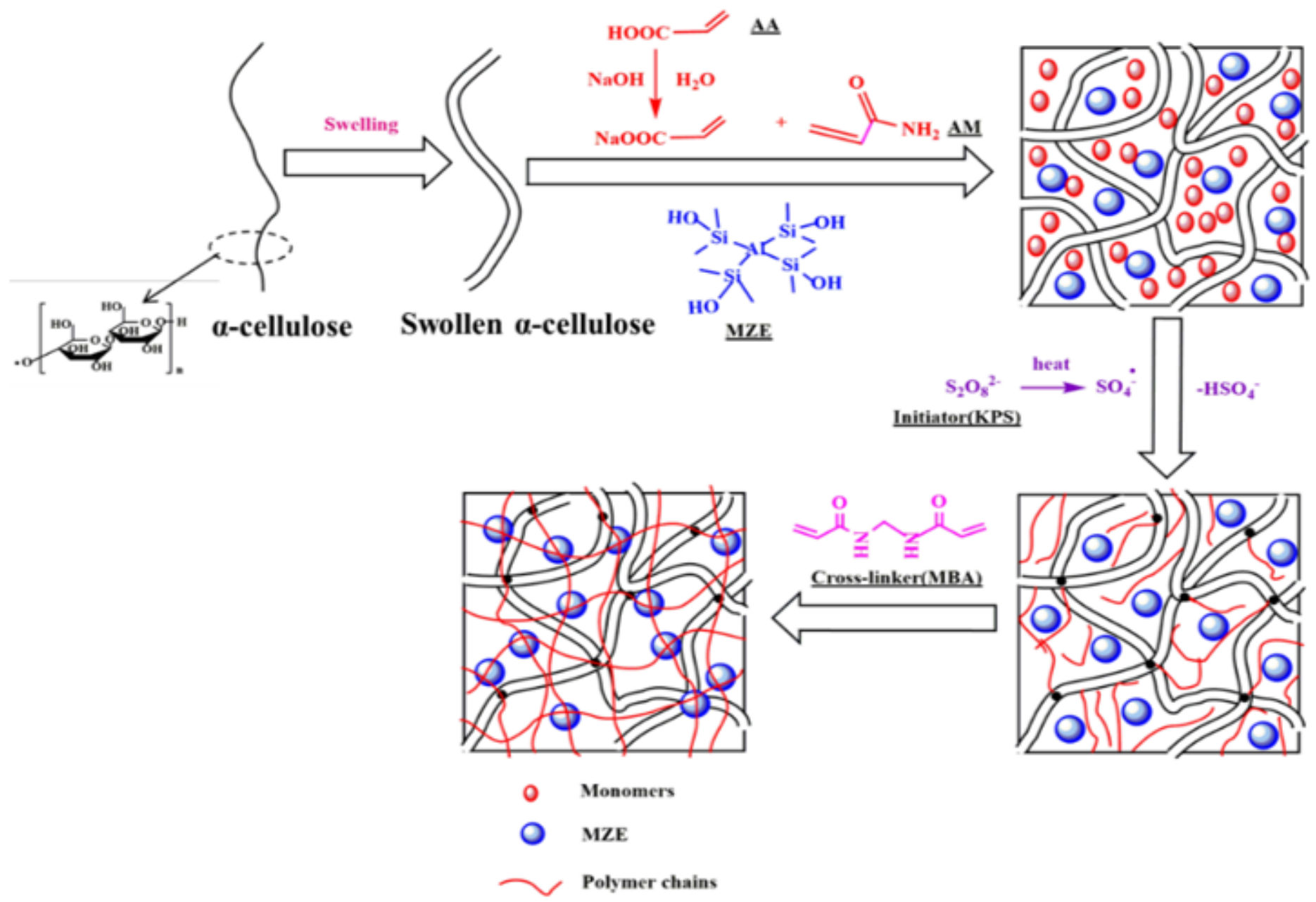

Figure 1

A proposed schematic of the synthesis of novel SAP composites 


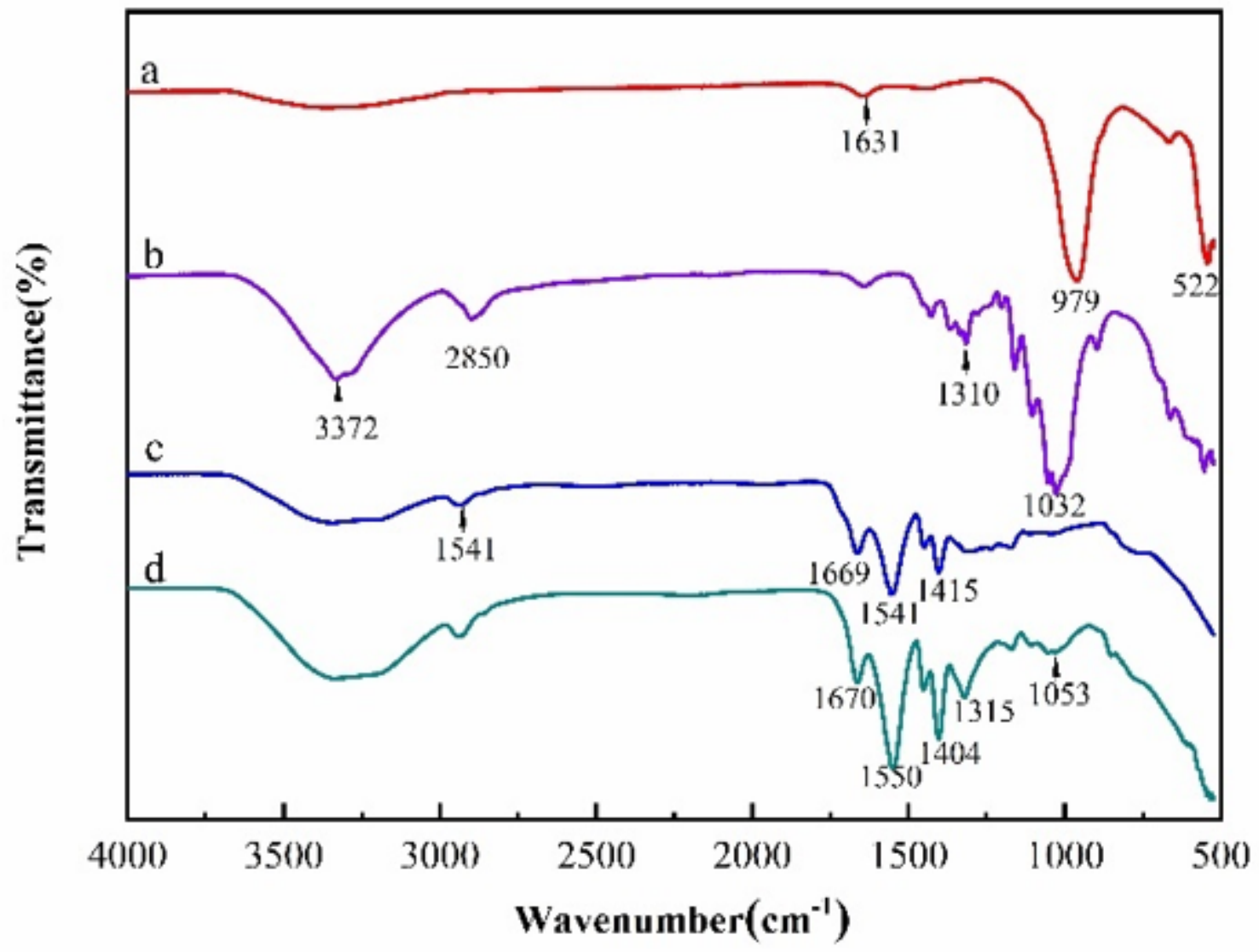

Figure 2

FTIR spectrum of (a) MZE, (b) a-cellulose, (c) poly(AA-co-AM), (d) novel SAP composites 


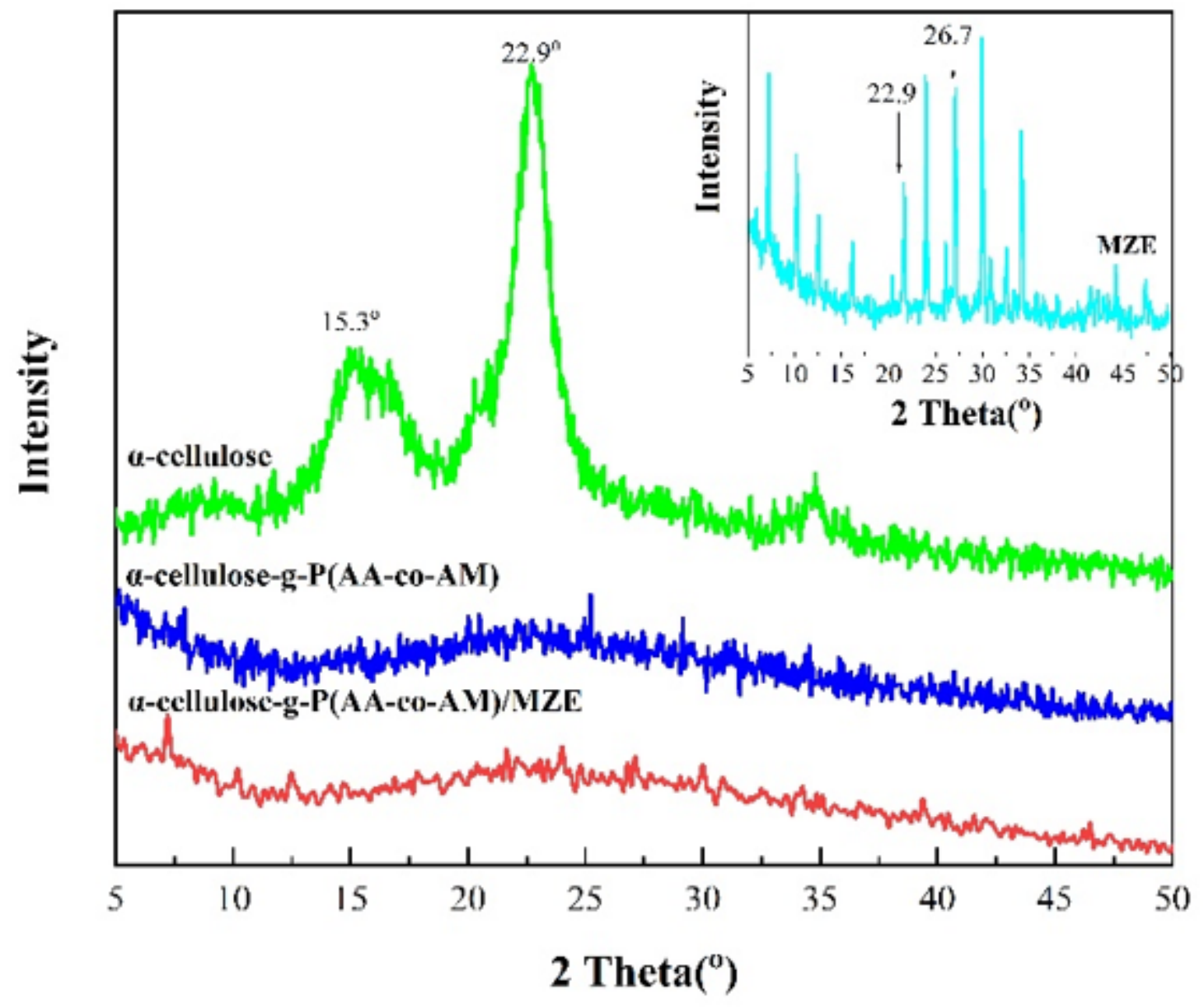

Figure 3

XRD patterns of MZE, a-cellulose, a-cellulose-g-poly(AA-co-AM) and novel SAP composites 


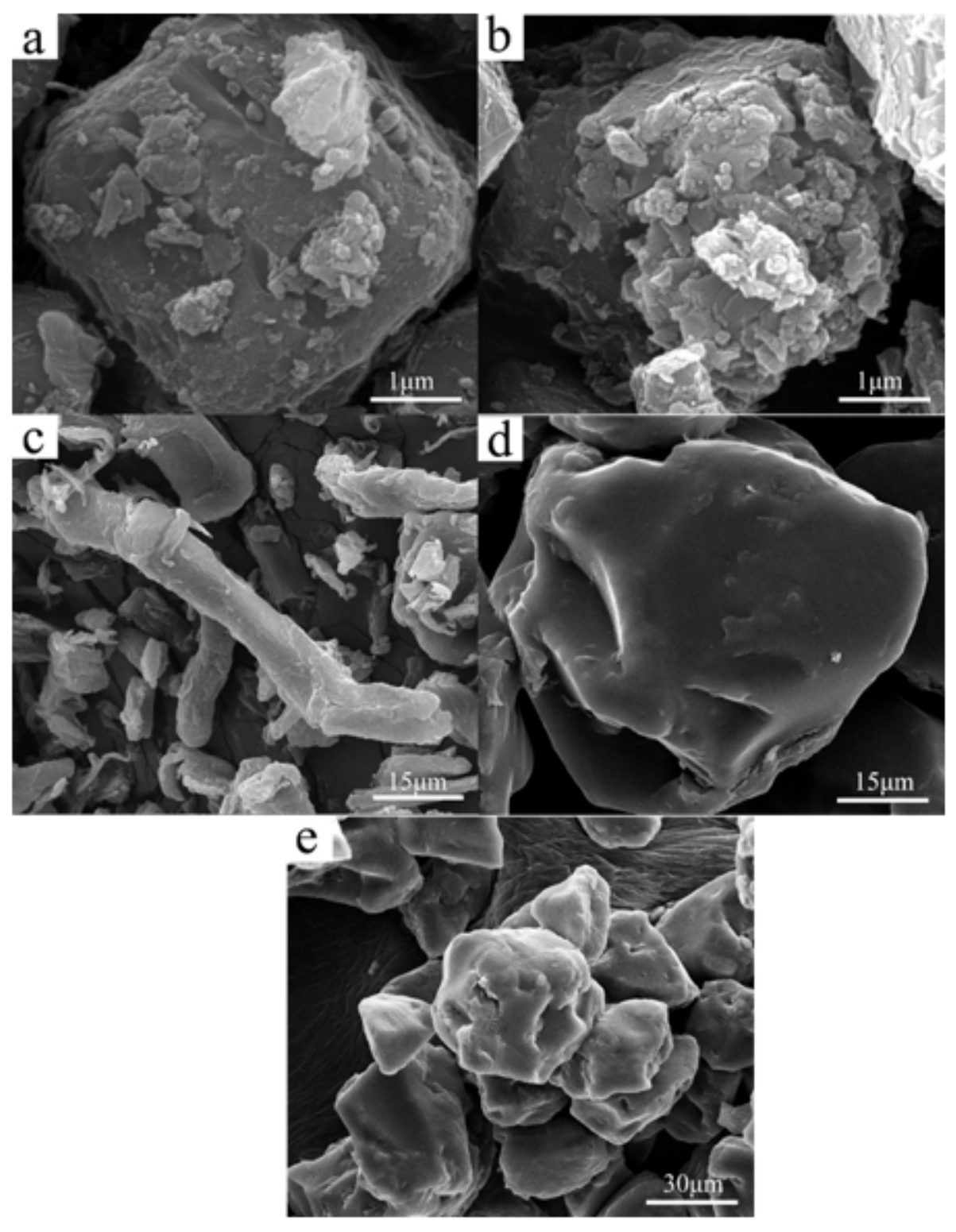

Figure 4

SEM pictures of (a) ZE, (b) MZE (c) a-cellulose, (d) a-cellulose-g-poly(AA-co-AM), (e) novel SAP composites 


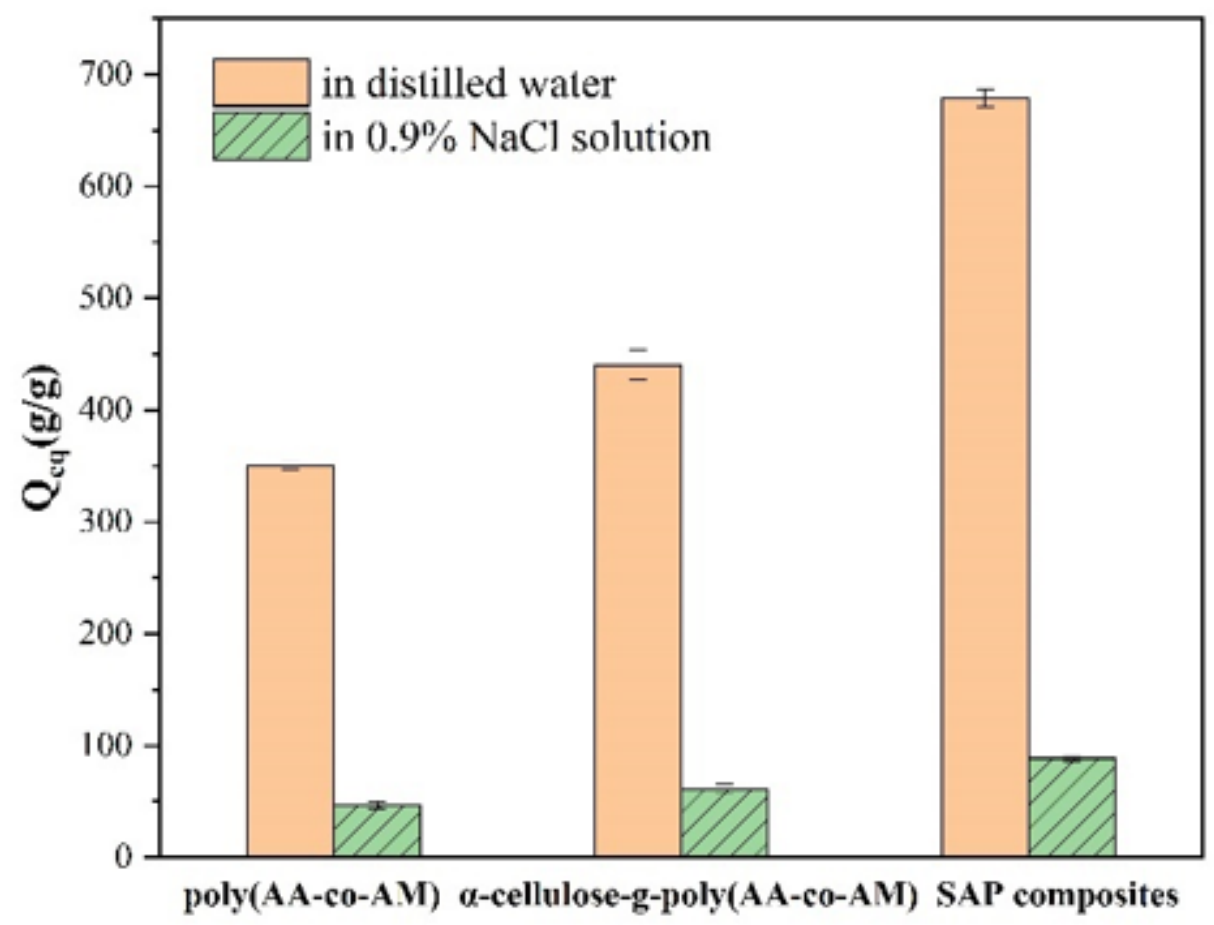

Figure 5

Water absorbency of poly(AA-co-AM), a-cellulose-g-poly(AA-co-AM), and novel SAP composites

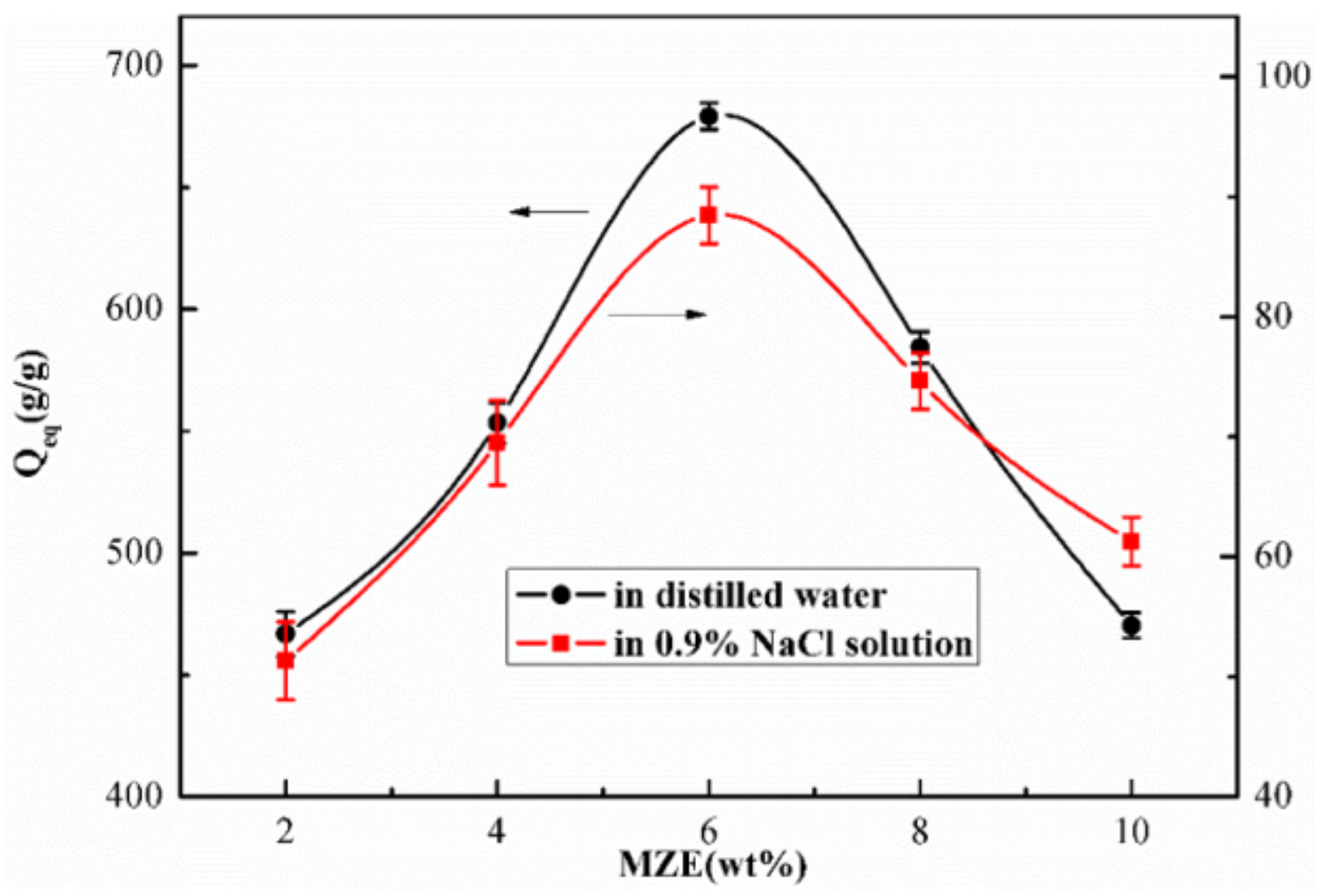

Figure 6 
Water absorbency of novel SAP composites with different MZE contents Swelling kinetics

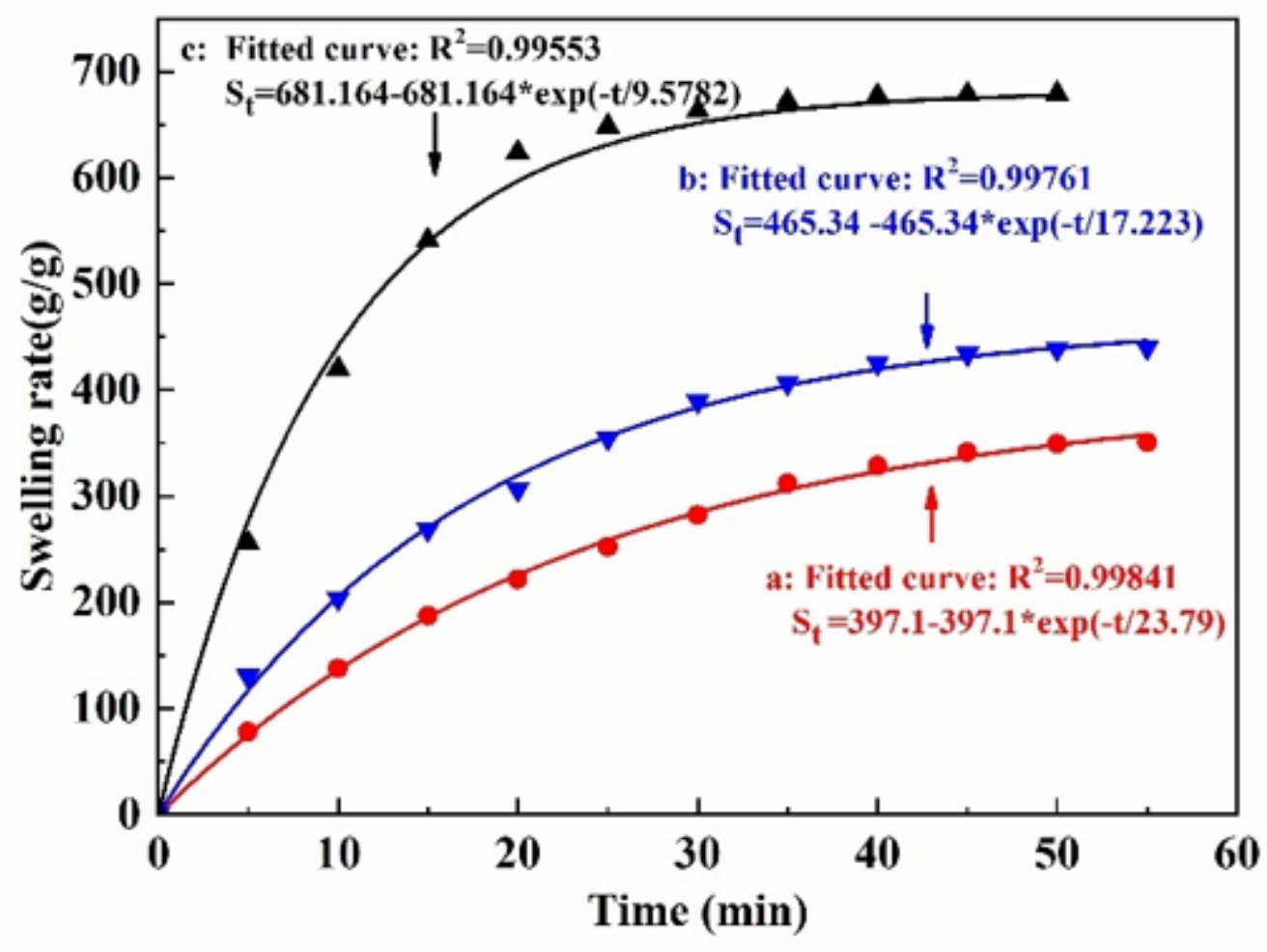

Figure 7

Swelling kinetic curves of (a) poly(AA-co-AM), (b) a-cellulose-g-poly(AA-co-AM), (c) novel SAP composites

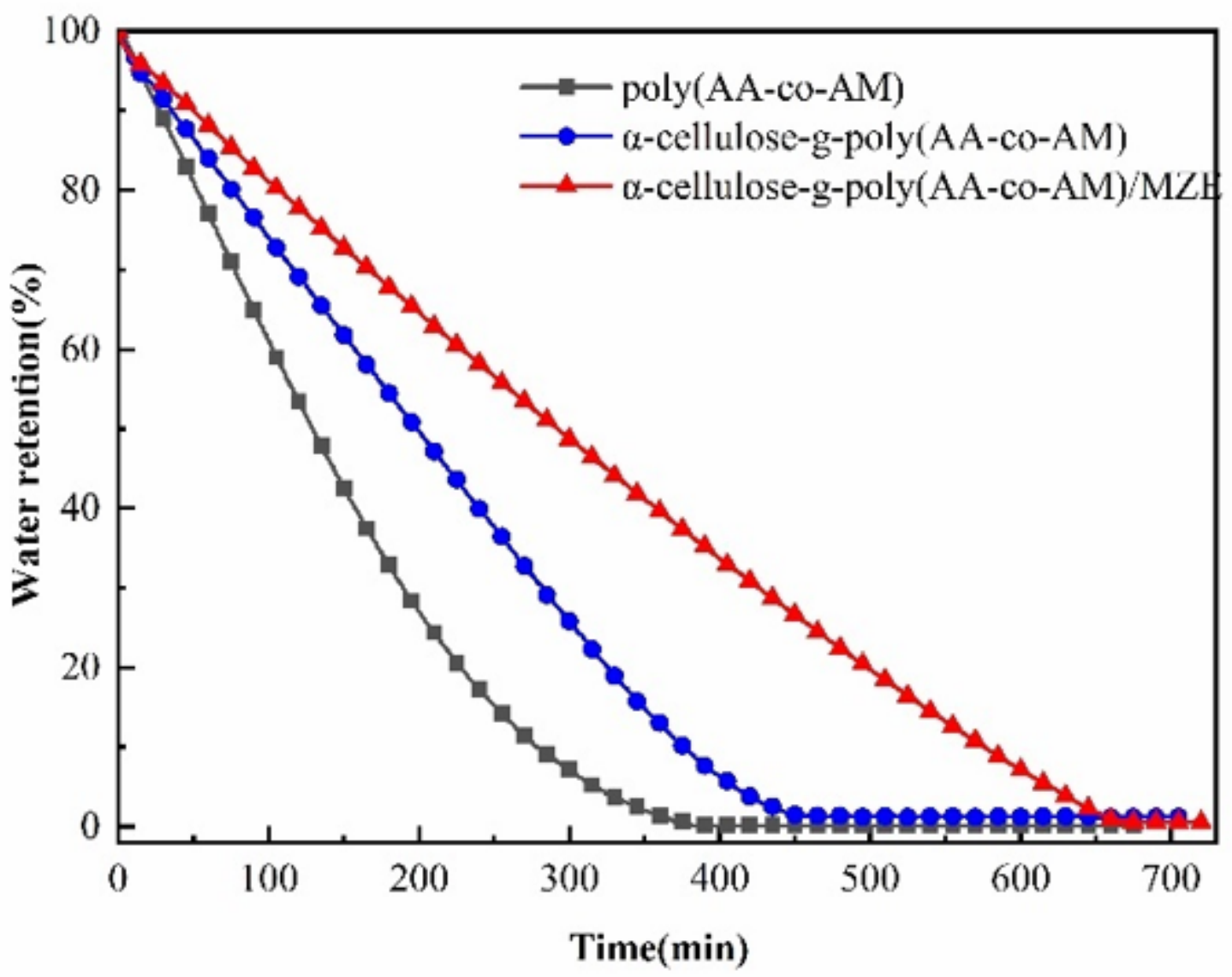


Figure 8

Water retention capacity of poly(AA-co-AM), a-cellulose-g-poly(AA-co-AM) and novel SAP composites

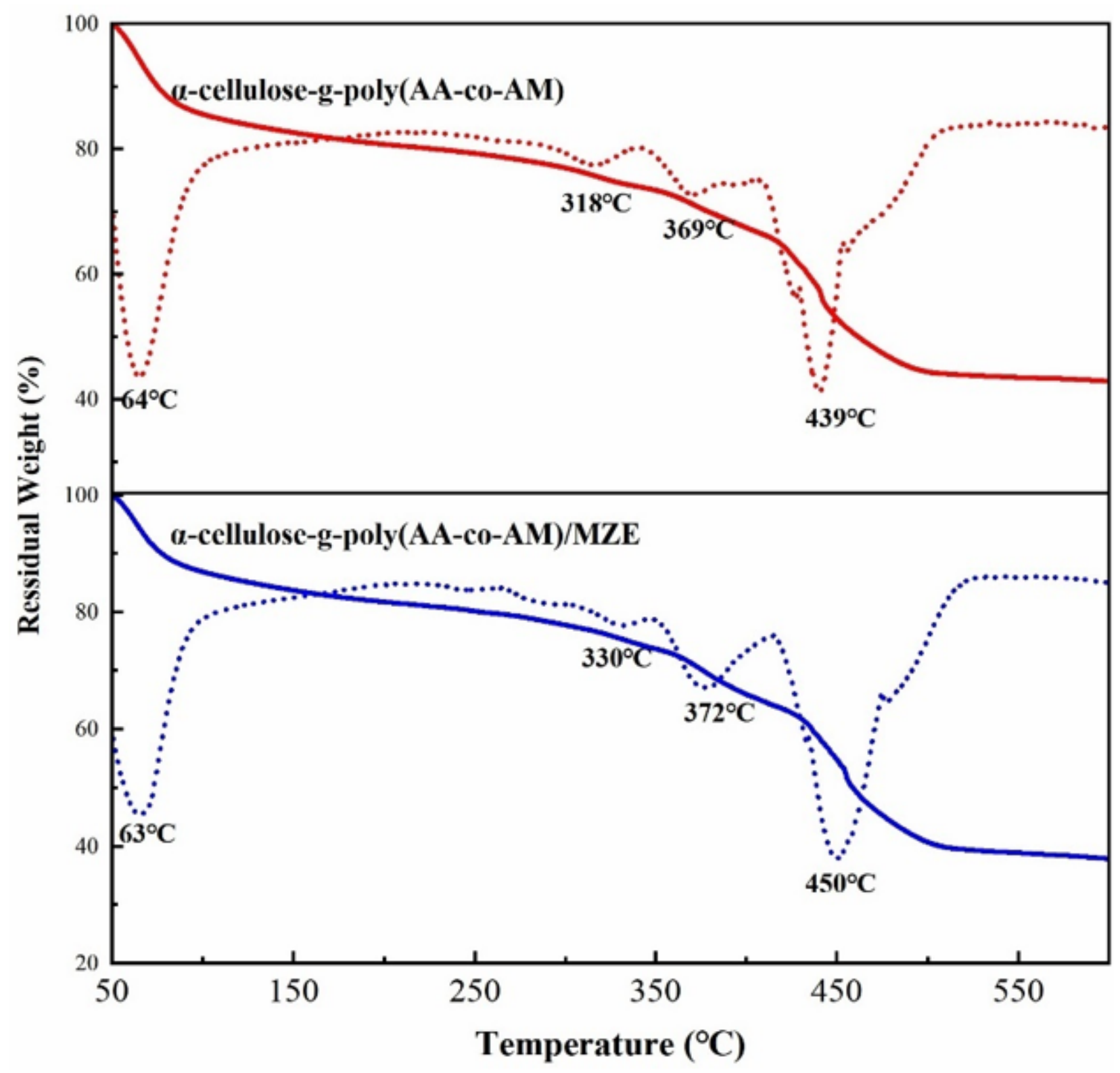

Figure 9

TG and DTG curves of a-cellulose-g-poly(AA-co-AM) and novel SAP composites 